\title{
PSYCHE
}

Vol. 76

March, 1969

No. I

\section{A REVIEW OF THE SPECIES OF SCARITES (ANTILLISCARIS), (COLEOPTERA: CARABIDAE) WITH NOTES ON \\ THEIR MORPHOLOGY AND EVOLUTION}

\author{
By T. F. HLavaC ${ }^{1}$ \\ Museum of Comparative Zoology, Harvard University
}

Recently, through the courtesy of Prof. R. A. Howard, Director of the Arnold Arboretum at Harvard University, the Museum of Comparative Zoology received a shipment of Coleoptera from the Luquillo Mountains of Puerto Rico, collected on "W. Peak" by R. A. McClain. Included in this material was a single specimen of the largest carabid in the Greater Antilles, representing a new species of Scarites (Antilliscaris), $35 \mathrm{~mm}$ in length. This behemoth is superficially different from but shares a unique set of characters with two known species of the subgenus from the mountains of Puerto Rico. The presence in the depauperate Puerto Rican montane carabid fauna of three species of $S$ carites raises questions about the ecology and evolution of these beetles. These questions have been approached through study of the comparative functional morphology of $S$. (Antilliscaris) and other Scarites subgenera and through preliminary observations and experiments on one adult collected during a recent trip to Puerto Rico.

Banninger (1949, p. I46) proposed the subgenus Antilliscaris for Scarites darlingtoni Banninger, S. mutchleri Banninger (both orig-

${ }^{1}$ I wish to thank Dr. P. J. Darlington, Jr., for suggesting this study, for advice and encouragement during its progress and for reading the manuscript. I am grateful to Dr. John F. Lawrence for reading the manuscript and for many helpful suggestions. Field facilities at the El Yunque Biological Station of the University of Puerto Rico were provided through the courtesy of Dr. Eric G. Matthews.

Field work on Puerto Rico was supported by NSF Grant GB 7346 to the Committee on Evolutionary Biology of the Department of Biology at Harvard University.

Published with the aid of a grant from the Museum of Comparative Zoology. 
inally considered to be of uncertain systematic position, I939, p. I48) and for $S$. danforthi Darlington. Banninger incorporated the new subgenus into his earlier key to the subgenera of Scarites (1937, pp. 123-128) and provided a key to separate the species.

Scarites subgenus Antilliscaris Banninger 1949, p. I36

Diagnosis: head: large, $37-59 \%$ of length of elytra. Mandibles: median carnassal regions large, basal molar area small with complex of interdigitating cusps, dorsal surface smooth. Eyes: small, height $30-50 \%$ of height of mandible. Antennae: long to very long for a Scarites, segment 4 similar to apical segments, dorsal and ventral setose areas with rough microsculpture and pair of narrow lateral glabrous regions without setae, sides flattened but not as distinctly as in segments 5-I I. Segment 3 circular in cross section with apical ring of setae as well as a number on the apical $2 / 3$ of the dorsal surface and a few setae, including some very large ones on the ventral surface (Fig. 13). Frontal plate grooved. Pterothorax: metasternum and metepisternum short, L/W of episternum $0.87-\mathrm{I} .3$, elytra fused together and to mesanotum, wings reduced, shorter than metanotum in mutchleri. Lateral edge of mesotibia with one large spine. Metepimeron: slender, pleural suture very faint externally; epimeron-elytra interlocking mechanism absent.

Distribution: montane rain forests of Puerto Rico.

Key to the species of $S$. (Antilliscaris) and to $S$. (?) darlingtoni Banninger

I. Mandibles with series of striations on dorsal surface (Fig. 7) darlingtoni

I' Mandibles: dorsal surface smooth (Figs. 6, IO, I I) 2

2. Elytral intervals $1,3,5$ and 7 with setiferous punctures. Dorsal surface of head with 15 setiferous punctures. Antennae short, extending about to posterior border of prothorax, $\mathrm{L} / \mathrm{W}$ of segments 6-ro less than r.I (Fig. 8) danforthi

2' Only elytral interval 3 with setiferous punctures. Dorsal surface of head with 6 or fewer setiferous punctures

3. Antennae extending to mesocoxae, $\mathrm{L} / \mathrm{W}$ of segments 6 - Io between I.3 and I.6 (Fig. 9). Slight impression at posterior end of scrobe. Lateral margin of pronotum with 5-6 pairs of setiferous punctures, L/W o.8o. Total length I2- $18 \mathrm{~mm}$ mutchleri

$3^{\prime}$ Antennae extending to first abdominal sternite, $\mathrm{L} / \mathrm{W}$ of segments 6-Io between I.8 and 2.3 (Figs. II, I2). Deep pit at posterior end of scrobe. Lateral margin of pronotum with 3 pairs of seti- 


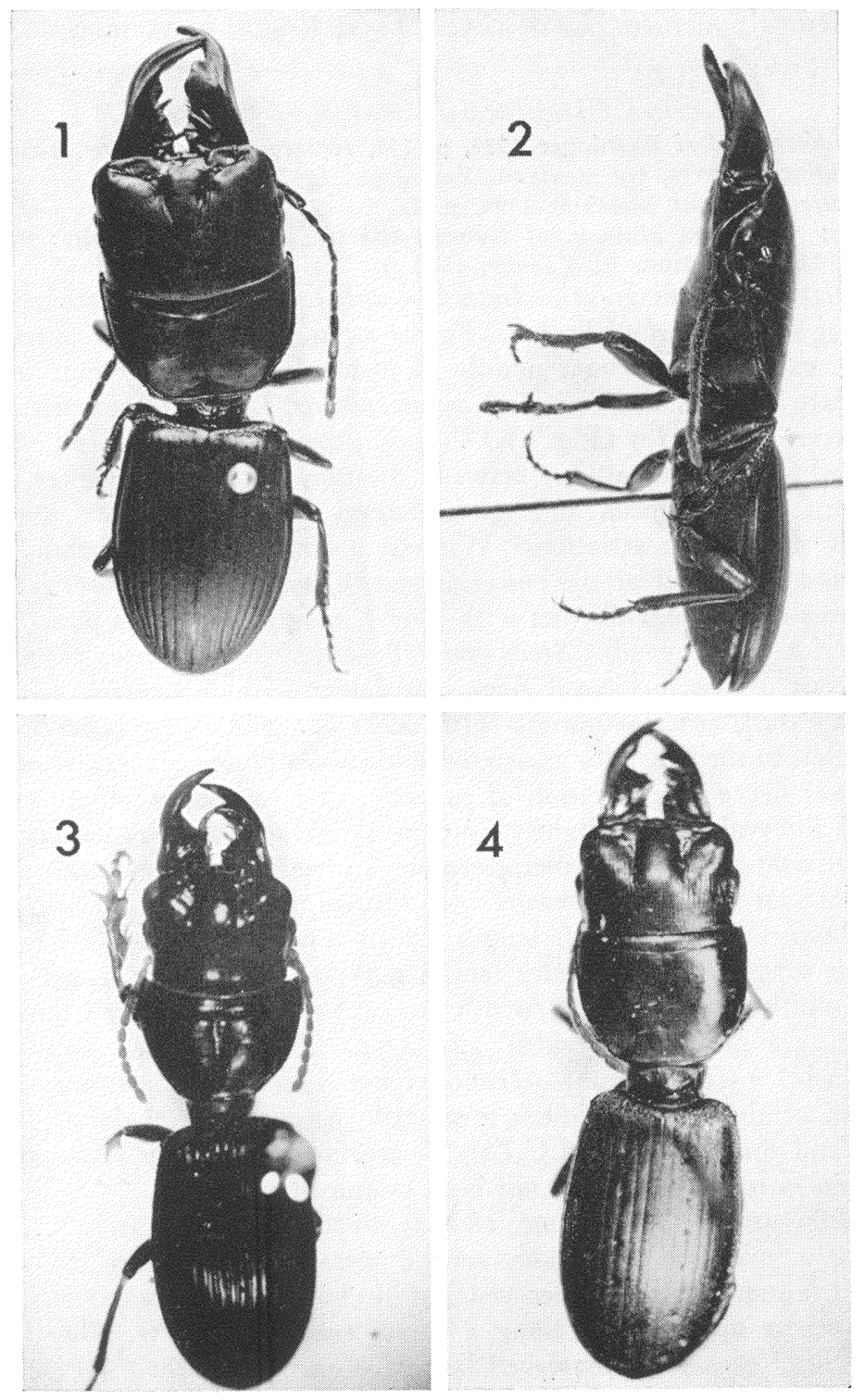

Figs. 1, 2-S. (Antilliscaris) megacephalus n. sp. Fig. $3-S$. (A.) danforthi. Fig. $4-S$. (A.) mutchleri. 
ferous punctures, $\mathrm{L} / \mathrm{W}$ 0.54. Total length $30-35 \mathrm{~mm}$. megacephalus n. sp.

Scarites (Antilliscaris) mutchleri Banninger

Scarites mutchleri Banninger 1939, p. 149, replacement name for montanus Mutchler 1934, not montanus Banninger, 1932.

Scarites montanus Mutchler 1934, p. 1.

Type: American Museum of Natural History, seen; type locality: Puerto Rico, Luquillo Mtns., El Yunque, $1800 \mathrm{ft}$.

Description (diagnostic characters only). With the characteristics of the subgenus Antilliscaris. Forms as in Fig. 4. Head: antennae long, extending to about middle of peduncle, apical segments intermediate between danforthi and megacephalus, $\mathrm{L} / \mathrm{W}$ of segments 4-1O between I.3 and I.9 (Fig. 9). Vertex: 3 pair of setae, clypeal, supraorbital and a pair halfway between the two and closer together than either. Lateroclypeus and antero-lateral halves of vertex with a series of irregular striations. Without a large depression behind the eye and a deep pit at the posterior end of scrobe. Prothorax: lateral grooves narrow but distinct with 5 or 7 pairs of setiferous punctures, posterior angles small. Sternum: 6-8 setiferous punctures clustered in front of the intercoxal spine, the latter with 6-8 setae. Elytra: surface dull, anterior margin with dense band of coarse tubercles in addition to the tubercles associated with setiferous punctures. Lateral groove: dense concentration of tubercles, 7-8 setiferous punctures on third interval. Striae lightly impressed. Pterothorax: mesasternum, 2 setiferous punctures; metasternum 6-7 setiferous punctures. $A b$ domen: Ist and 2nd intersegmental sutures normal.

Measurements. Head: length 2.7-3.1 mm, width 3.6-4.0, length/ width 0.75-0.77. Mandible: length 2.3-3.o. Prothorax: length 3.I3.5, width 4.0-4.6, length/width 0.77-0.76. Elytra: length 6.9-7.9, width 4.2-4.8, length/width I.64-I.64. Total length (including peduncle) I5.4-18.0 mm. Measurements reported: extremes in total length of the four specimens measured. Specimens examined: holotype and three others (M.C.Z.). A specimen, currently alive, about I $2 \mathrm{~mm}$ in total length, has not been examined critically.

Distribution: El Yunque, I $800 \mathrm{ft}$. to summit (3493 ft.).

Larva: Three presumably second instar Scarites were collected on El Yunque, one in a decayed $\log$ in cloud forest c. $2200 \mathrm{ft}$., and two others under rocks along a forest trail c. $3200 \mathrm{ft}$. Based on size (head capsule of preserved larve $1.9 \mathrm{~mm}$ wide) these larvae are probably mutchleri.

Scarites (Antilliscaris) megacephalus n. sp.

Holotype: a male M.C.Z. No. 31710. Type locality: Puerto 

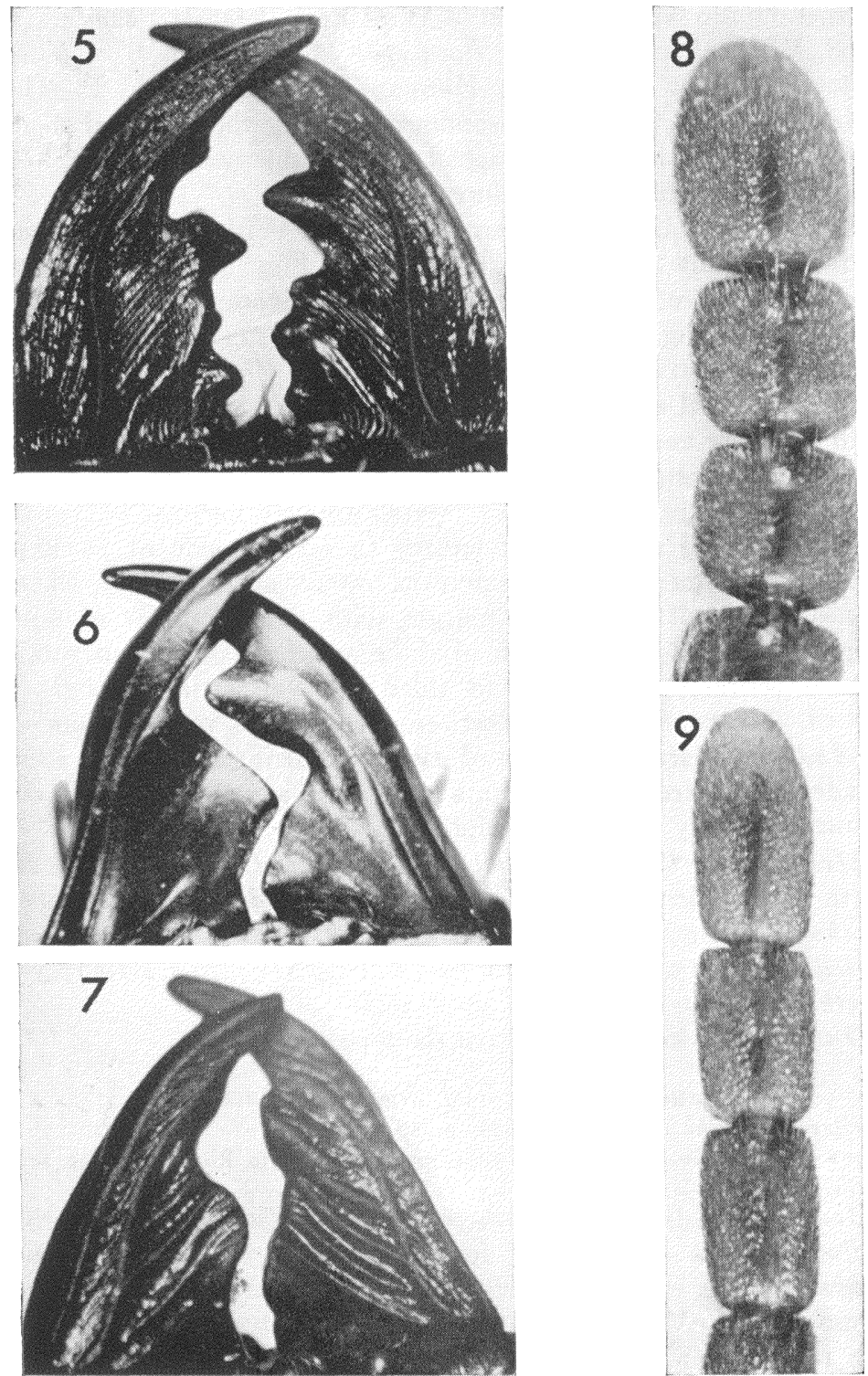

Fig. 5-Mandibles, S. (s. s.) substriatus. Fig. 6-Mandibles, S. (A.) mutchleri. Fig. 7 -Mandibles, $S$. (?) darlingtoni. Fig. 8-Antennal apex, $S$. (A.) danforthi. Fig. 9-Antennal apex, S. (A.) mutchleri. 
Rico, Luquillo Mountains, top of West Peak, $3447 \mathrm{ft}$., May or June 1968, W. C. McClain Coll. Paratype: M.C.Z.; Sex ?, El Yunque c. 3200 ft., Feb. 1969, L. H. Herman Jr., B. C. and T. F. Hlavac collectors. This fragmented specimen, missing the antennal flagella, max:llae, several legs and the apical abdominal segments, was collected dead under a stone along a forest trail.

Description (diagnostic characters only). With the characteristics of the subgenus Antilliscaris (form as in Figs. I, 2). Head: very large as compared to the relatively squat pronotum and elytra. Antennae very long, extend to first abdominal sternite, length/width of segments 4-IO between I.8-2.3 (Fig. I2). Vertex: pair of clypeal and supraorbital setiferous punctures. With a deep, broad depression behind the eye and a deep puncture at the posterior end of the scrobe. Lateroclypeus and antero-lateral halves of vertex with series of irregular situations. Prothorax: lateral grooves narrow but distinct with 3 pairs of setiferous punctures ( 4 on left side of paratype). Sternum without setiferous punctures, intercoxal spine with i2. Elytra: surface dull. Anterior: margin with small number of minute tubercles about I/ 3 the width of those associated with punctures; I pair of setiferous punctures in third interval, striae strongly impressed. Mesasternum with 2 setiferous punctures, metasternum with 4. Abdomen: lateral portions of Ist and 2nd intersegmental sutures broadened and deepened to form a large fossa, sutures separating other segments slightly enlarged laterally.

Measurments of holotype and paratype: Head: length 7.5-7.1 mm, width 9.5-7.2 length/width 0.79-0.98; Mandible: length 7.0-5.7; Prothorax: length 5.5-5.0, width I0.I-8.I, length/width 0.54-0.62; Elytra: length 13.0-I2.5, width 9.3-7.9, length/width I.4-I.58; Total length (including peduncle): $35-30 \mathrm{~mm}$.

Distribution: known only from the type series.

Scarites (Antilliscaris) danforthi Darlington

Scarites danforthi Darlington 1939, p. 80.

Type: M.C.Z. No. 23,501 seen; type locality: Puerto Rico, Maricao forest, c. $3000 \mathrm{ft}$.

Description (diagnostic characters only). With the characteristics of the subgenus Antilliscaris, form as in Fig. 3. Head: antennae, relatively short, extend to posterior margin of prothorax, apical segments squat, L/W of segments 4-Io less than I.I (Fig. 8). Vertex with 15 setiferous punctures including 2 pair of supraorbitals. Lateroclypeus and anterolateral halves of vertex without series of irregular situations. Without a large depression behind eye and deep pit at posterior end of scrobe. Prothorax: lateral groove indistinct near 


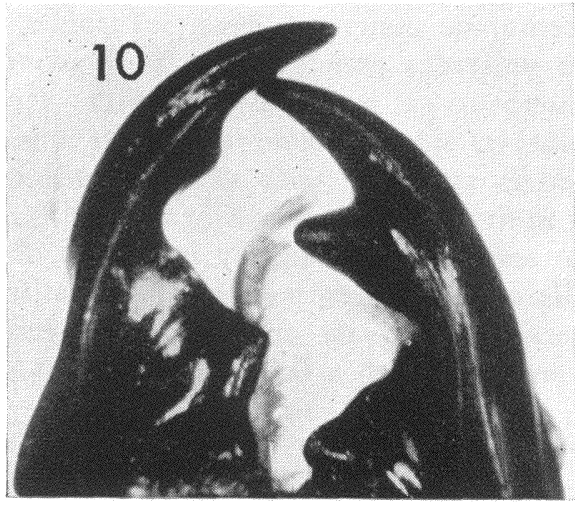

12
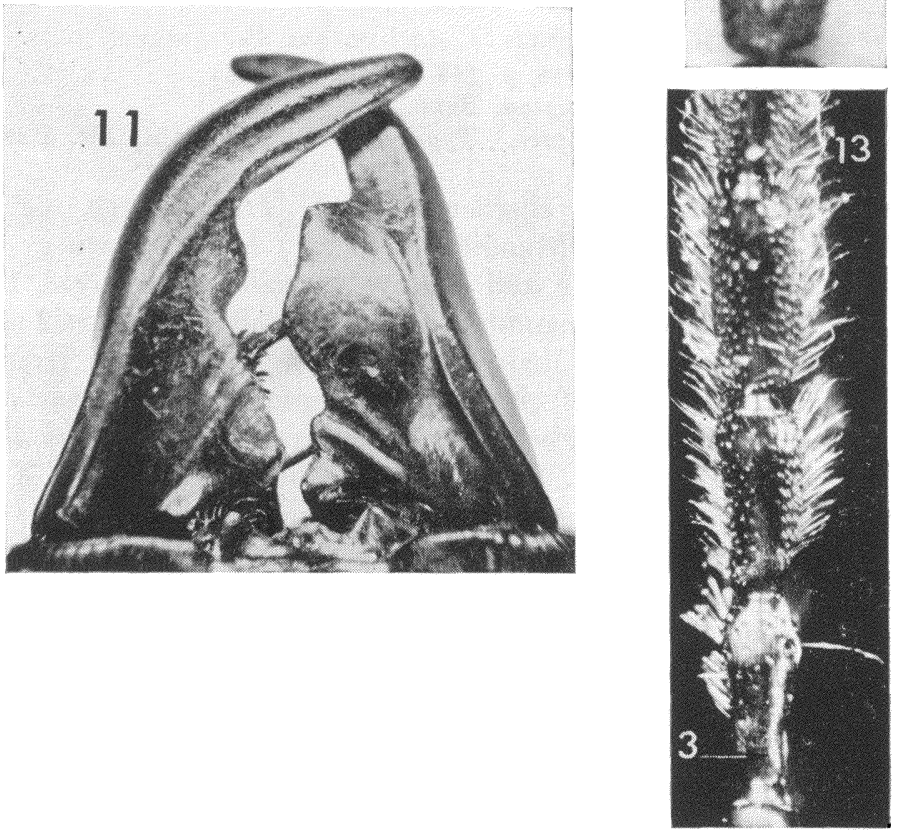

Fig. $10-$ Mandibles, $S$. (A.) danforthi

Fig. 11 - Mandibles, $S$. (A.) megacephalus n. sp.

Fig. 12 - Antennal apex, $S$. (A.) megacephalus n. sp.

Fig. 13-Antennal segments 3, 4, 5, $S$. (A.) megacephalus n. sp. 
middle, with 5 pairs of setiferous punctures, posterior angles very small. Sternum: about 20 setiferous punctures clustered about the midline, intercoxal spine with IO-I2 setiferous punctures. Elytra: surface shiny. Anterior margin: small number of minute tubercles $\mathrm{I} / 3$ the width of the tubercles associated with setiferous punctures, 4 or 5 setiferous punctures in first interval, 7 or 8 in third, 6,7 , or 8 in fifth, and 5, 6, or 7 in seventh, striae lightly impressed. Pterothorax: mesasternum 8 setiferous punctures, metasternum 6 setiferous punctures. Abdomen: lateral parts of Ist and 2nd intersegmental sutures broadened and deepened to form a large fossa, other sutures enlarged laterally.

Measurements of holotype and paratype. Head: length 2.5-3.0 $\mathrm{mm}$, width 3.I-3.5, length/width $0.8 \mathrm{I}-0.86$. Mandibles: 2.2-2.6. Prothorax: length 2.7-3.0, width 3.9-4.0, length/width o.69-0.67. Elytra: length 6.7-6.7, width 4.0-4.o, length/width I.68-1.68. Total length (including peduncle) I4.6-16.0.

Distribution: known only from the type series.

Scarites (subgenus?) darlingtoni Banninger

Scarites darlingtoni Bann. 1935, p. 159.

Scarites (Antilliscaris) darlingtoni Bann. 1949, p. 137.

Type: M.C.Z. No. 21,797, seen. Type locality: N. Haiti, Mt. Basil, c. $4700 \mathrm{ft}$.

Description (diagnostic characters only). Head: large, $43 \%$ of the length of the elytra. Mandibles (Fig. 7) heavily worn in type, with striate dorsal surface and relatively small molar area. Eyes: $50 \%$ of the height of the mandible. Antennae: absent in type. Lateroclypeus and antero-lateral halves of vertex with series of irregular striations. Vertex: pair of clypeal and supraorbital setiferous punctures. Without depression behind eye and large puncture at posterior end of scrobe. Prothorax: lateral grooves distinct with 7 or 8 setiferous punctures. Sternum: without setiferous punctures but with I 7 on intercoxal spine. Elytra: surface polished. Anterior margin with small number of tubercles about $\mathrm{I} / 3$ the width of those associated with punctures. Lateral groove rugose. 8 setiferous punctures in third interval, striae impressed. Pterothorax: reduced, elytra fused together and to mesanotum, wings shorter than the metanotum. Metepisternum and metepimeron absent in type, L/W about I. Mesasternum without setae and metasternum with 6 . Abdomen: intersegmental sutures normal.

Measurements of holotype: Head: length $4.0 \mathrm{~mm}$, width $5 . \mathrm{I}$, length/width 0.78 . Mandible: length 3.0. Prothorax: length 4.0, width 5.6, length/width 0.72 . Elytra: length 9.5, width 6.3, length/ 
width I.50. Total length (including peduncle) 21.8. Specimen examined: holotype.

Comments: known from the appendageless fragments of two specimens. I regard it as of uncertain subgeneric position for three reasons. The structures containing the major diagnostic characters of Antilliscaris, antennae and metepimeron, are absent in the available material. A major similarity between Antilliscaris and darlingtoni is the reduction of the flight mechanism. Flightlessness and, in extenso, large-scale reorganization of the flight mechanism occur with high frequency among montane carabids (Darlington 1943), which argues against uniting darlingtoni with Antilliscaris in the absence of other evidence. Furthermore, there is a gap between Antilliscaris and darlingtoni in the dorsal surface of the mandibles (Figs. 5, 6, 7, IO, II).

\section{Discussion}

Several character states in Antilliscaris range from atypical to unique for a Scarites $s$. $l$. Many of these differences are found in the locomotory system or are peripheral to it. This raises questions about associated behavioral and ecological differences. In an attempt to list some of the possible answers to these questions, particular configurations of Antilliscaris are contrasted with $S$. (s. s.) substriatus Haldemann and subterraneus Fabricius. This is not done because I feel that these 2 species are closely related to Antilliscaris, but because both fly and burrow (Hlavac, 1967) and can be used as a base line in interpreting the morphology of Antilliscaris.

antennae: The antennae of Antilliscaris are unusual in three respects: in length, in the setation of the 4 th segment and in the relative narrowness of the lateral glabrous areas. An increase in the size of the antennae can be documented in terms of elongation of individual segments, as expressed by length/width, and in terms of increase relative to body size. The ranges of length/width of segments 6-10 is 0.9-1.I in danforthi, I.35-1.55 in substriatus, I.3-г.6 in mutchleri, and 1.8-2.3 in megacephalus. The antennae reach the procoxae in substriatus, the posterior margin of the prothorax in danforthi, and middle of the peduncle in mutchleri and the first abdominal sternite in megacephalus. As compared to substriatus, the antennae of danforthi are longer and the individual apical segments are much wider. Assuming that there are no major differences between the relative widths of the first segment in the above species, then a measure of width of the antennal apex can be expressed as width of an apical segment/width of segment I. Using width of the 8th segment in this ratio, the figures are 0.72 for substriatus and megacephalus, 0.93 for mutchleri and I.I for danforthi. 
To summarize, the antennae of all Antilliscaris are longer than substriatus. The apical segments are broad in danforthi, elongate in megacephalus, with mutchleri and substriatus intermediate.

In substriatus, $28 \%$ of the antennae extends beyond the mandible. When burrowing the antennae are held agaist the head wall causing the apical segments to curve in a broad U. In megacephalus $50 \%$ of the antennae extends beyond the mandible. If this species burrows the antennae would be doubled over while the animal is working. Short antennae are characteristic of the many diverse taxa of burrowing Coleoptera which have independently evolved a pedunculate body form. The long antennae of Antilliscaris and particularly megacephalus strongly suggests that these beetles do not burrow.

Captive substriatus and subterraneus and many geophilious carabids apparently do not react visually to prey; olfactory and/or tactile reactions have been observed upon physical contact. While patrolling a burrow system, the antennae of subterraneus are held parallel to the long axis; the maximum sweep width is limited by the diameter of the burrow. On the surface, they are held approximately $45^{\circ}$ from the long axis. If only short range olfactory and tactile stimuli are used to recognize prey, then finding it will be a function of the distance travelled and the width of the band through which the sensory equipment move. On the surface, long antennae are clearly adaptive in increasing the width of the search band, and may partially explain the condition in Antilliscaris.

There is a gap in the setation and microsculpture of the first 4 segments as contrasted to segments 5-I I in all subgenera except $A n$ tilliscaris and Typhloscaris from the mountains of E. Africa. In most subgenera, segments I-4 have few or no setae and are circular in cross section, while segments 5-I I are flattened laterally and have a dense covering of setae and rough microsculpture except for a glabrous, asetose median stripe. Segment 4 of Antilliscaris is intermediate in shape between segments 3 and 5 and has the surface organization of the apical segments.

The surface of the apical segments is divided into two distinct structural and, probably, functional areas. As seen in lateral view, a pair of setose bands with rough microsculpture extend along the dorsum and venter of the apical segments; they are united near the distal end of the IIth segment (Figs. 8, 9, I2). Between the setose bands is an asetose median band with smooth microsculpture. Members of the genus Scarites differ widely in the distribution of these two surface types; in $S$. (Antilliscaris) the median band is $25-30 \%$ of the width, but $55 \%$ in substriatus. 
The elongate and/or broad apical segments and the state of the 4th segment in Antilliscaris represent an increase in surface area of antennal apex over substriatus. Due to differences in distribution of surface types, there is a large increase in setose areas, which can be interpreted as an intensification of the functions served by this region.

EYES: The eyes of Antilliscaris are small, 30-50\% the height of the mandible, vs. $100 \%$ in substriatus, and are nearly circular except in danforthi where the posterior border is nearly straight. Smith (I964, p. I I6) stated that the eyes of flightless carabids are not reduced, except for cave inhabiting species; this is clearly not the case for montane Scarites or for the montane carabid fauna of New Guinea (P. J. Darlington Jr., personal communication). Eye reduction in Scarites seems to have come about either from a reduction in diameter (Antilliscaris) or from diameter reduction and shortening the anterior posterior axis, giving the eyes of $S$. (Typhloscaris) and $S$. (Taeniolobus) cubanae Banninger a peculiar slit-like appearance. MANDIBLES: The mandibles of scaritine carabids are structurally complex and can be divided into three functional regions, an apical and 2 medial carnassal areas and a basal molar part. Antilliscaris and Scarites s. s. represent extremes in the relative sizes of the latter 2 of these areas (Figs. 14, 15). In an unworn specimen of substriatus (Fig. 5) the apical carnassal is $34 \%$, the median carnassals $26 \%$ and the molar $40 \%$ of the total length (perpendicular distance between apex and base); while in Antilliscaris (Figs. 6, IO, II) the apical carnassal ranges from $24-34 \%$ the median carnassals from
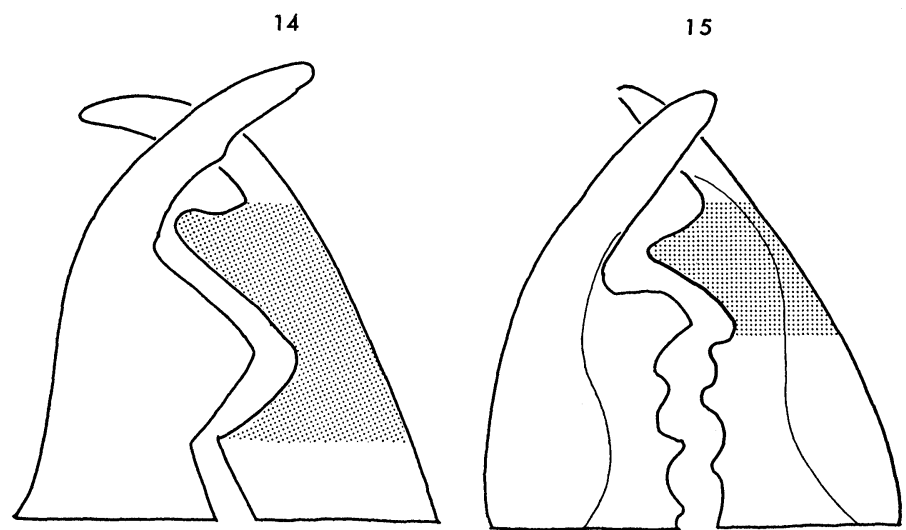

Fig. 14. - Mandibles, S. (Antilliscaris). Fig. 15-Mandibles, S. (s. s.). Medial carnassal areas shaded. 
$45-59 \%$ and the basal molar part ranges from $17-2$ I $\%$ of the total length. In Antilliscaris then, the median caranassals are twice as large and the molar area half the relative size of the corresponding areas of substriatus.

If it can be assumed that these structural differences correlate with behavioral differences, then the condition in Antilliscaris may reflect 3 types of such differences. The mandibles of substriatus and subterraneus are used to loosen material from the head wall of the burrow, in mating and, of course, in feeding. Some substrate loosened by the protibia is compressed further and compacted into a part of the stable burrow system by the vertex of the head and pronotum (Hlavac, 1967, and unpublished observations). The smaller molar area in Antilliscaris could indicate either that these animals burrow through a less dense, more easily compacted, substrate than Scarites $s$. $s$. or that they do not burrow at all. Secondly, the differences in mandible morphology may reflect differences in feeding behavior (see comments on body form, below) or mating.

FLIGHT MECHANISM: Antilliscaris represents an extreme point in the atrophy of the flight mechanism. The fused elytra are immovably joined to the mesathorax at two points, the posterior part of the mesatergum is tucked around and closely pressed against the anterior contours of the elytral cavity and secondly, the elytral hinge mechanism is solidly fused to the anterior part of the mesatergum.

The volume enclosed by the metathorax is reduced; externally, this is seen most clearly by comparing the relative size of the lateral portion of the sternum and the $\mathrm{L} / \mathrm{W}$ ratio of the episternum in flying and wingless species. In substriatus the narrowest lateral part of the sternum is about half the mid-line length and the $\mathrm{L} / \mathrm{W}$ of the episternum is about 4 , whereas in mutchleri the lateral portion is $20 \%$ of the mid-line length and the $\mathrm{L} / \mathrm{W}$ of the episternum is about I. The central part of the sternum is also shortened in Antilliscaris but less dramatically; the mid-line in substriatus is equal to the length of the first $3 \mathrm{I} / 2$ abdominal sternites while in mutchleri it is equal to the length of the first $22 / 3$ abdominal segments. The vestigial wings of mutchleri are very small $(.375 \times . \mathrm{IOO} \mathrm{mm})$ and circular in cross section in a specimen examined in fluid.

In the Scaritini there are usually 3 lateral elytra-thorax and abdomen interlocking mechanisms. (Hlavac, unpublished observations.) The anterior lateral edges of the elytra fit into grooves on the dorsal rim of the mesepisternum, mesepimeron and metepisternum (Fig. I 7 ). The dorsal part of the metepimeron slopes inwards; the elytra curve slightly outwards at this point and rest on top of the flat surface of 
the epimeron. An internal elytral carina extends from just behind the level of the epimeron to the elytral apex and is enlarged posteriorly forming the internal plica. The carina rests against the edge of the infolded abdominal sternites.

Antilliscaris differs from all other subgenera of Scarites examined, including many flightless species, in that the dorsal part of the metepimeron is in the same plane as the episternum and the dorsal groove extends along the epimeron, i. e. the elytra-epimeron interlocking mechanism is absent, becoming part of the elytra-episternum device (Fig. I 8).

16

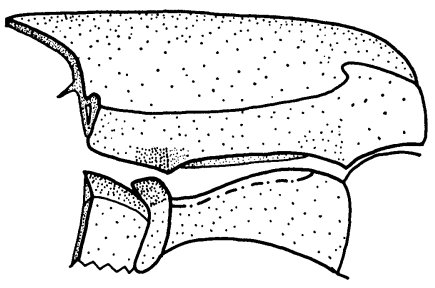

17

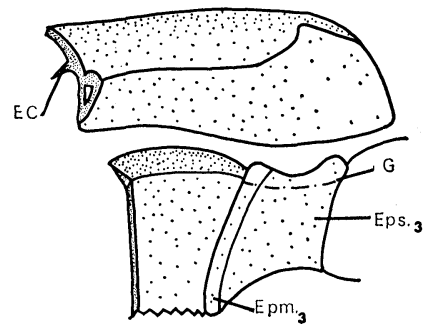

Fig. 16-Elytra-metathorax interlocking mechanism S. (s. s.) substriatus

Fig. 17 - Elytra-metathorax interlocking mechanism, S. (Antilliscaris) (EC, internal carina of elytra; $\mathrm{Epm}_{3}$, metepimeron; $\mathrm{Eps}_{3}$, metepisternum; $\mathrm{G}$, metapleural groove)

In burrowing and substrate dwelling Coleoptera, the elytral interlocking mechanisms maintain the structural integrity of the elytrabody joint against the forces generated in moving through a dense material. Lack of an integral portion of this mechanism in Antilliscaris can be explained in two, non-mutually exclusive manners. If the ancestral stock were not a highly adapted burrower (see below), then loss of epimeron-elytra joint could be due to neutral selection pressure for structural integrity. Or, secondly, after becoming flightless, the primary interlocking mechanism becomes the fusion of the elytra to each other and to the mesothorax; loss of epimeron-elytra joint represents post-adaptational adjustment; there is no need to assume a change in selection pressure for structural integrity.

BODY FORM: $S$. (A.) megacephalus and $S$. (s. s.) substriatus represent extremes in body proportions with mutchleri and danforthi intermediate. The outline of megacephalus can be derived from that of substriatus by shortening the pterothorax and abdomen (Elytra $\mathrm{L} / \mathrm{W}$ from $\mathrm{I} .8$ to $\mathrm{I} .4$ in $S$. and $A$. respectively) and the prothorax 
( $\mathrm{L} / \mathrm{W}$ from 0.7 to 0.5 ) and by increasing the size of the head until it is $\mathrm{I} .36$ the length of the prothorax ( 0.82 in substriatus) and until the length of head and mandibles is I.I the length of the elytra ( 0.6 in substriatus).

A partial explanation of the shortening of the elytra is the atrophy of the flight mechanism. Differences in size between the head and prothorax can be looked at in terms of differences in muscle volume, i. e., a relative decrease in volume in the prothorax and a relative increase in the head. The prothorax houses most of the muscle volume responsible for its movement as well as that which moves the head and proleg (Larsen, 1966, p. 140), while the head encloses muscles responsible for the movement of its appendages. Ventrodorsal rotation of the head and prothorax are principal actions in burrowing, decrease in muscle volume for performing these actions indicates a shift in or absence of burrowing behavior. The large head implies a large mandibular adductor muscle and this along with the large carnassal areas of the mandibles could be an adaptation for seizing and breaking open large prey objects.

ECOLOGICAL SHIFT: Of the eight known montane species of carabids on Puerto Rico listed below, three are Scarites, and, with $O x y$ drepanus coamensis Mutchler, scaritines make up 50\% of the known carabid fauna. On Jamaica, an island of similar size (4500 sq. mi. vs. 3400 for P. R.) I 7 montane restricted species are known, nine of which are Colpodes; there are no Scarites (Darlington, I94I). As currently known, the montane biota of Puerto Rico is unique in the Greater Antilles in not having a large number of ecologically variable Colpodes. The size range of Puerto Rican species is 2.0 to $35 \mathrm{~mm}$ with the following distribution:

I-5 mm, 4 spp., Oxydrepanus coamensis Mutchler, $2 \mathrm{~mm}$;

Bembidion portoricense Darlington, $3.5 \mathrm{~mm}$;

Perigona microps Darlington, $2.9 \mathrm{~mm}$;

Phloeoxena portoricensis Darlington, $4.5 \mathrm{~mm}$.

5-IO mm, I sp., Colpodes estriatus Darlington, 4.0-6.7 mm.

I0-20 mm, 2 spp., Antilliscaris danforthi, I $4.6-16.0 \mathrm{~mm}$;

Antilliscaris mutchleri, I2.0-I8.0.

30 $+\mathrm{mm}$, S. (A.) megacephalus, 30-35 mm.

Antilliscaris is thus the largest carabid taxon, is at the apex of the size pyramid and is doubtless one of the top predators among ground invertebrates in this habitat.

It is useful to look at the mountains of Puerto Rico as habitat islands and to analyze the large Scarites fauna in the manner of MacArthur and Wilson (1967). In harmonic continental biotas, 
the large number of carabid species occupy three locomotory adaptive zones: arboreal (several tribes), ground in the broadest sense including soil surface and leaf litter (most tribes and species) and burrowing (primarily the Scaritini). All terrestrial zones available to a beetle are exploited by the Carabidae. Breadth of adaptation for the family and high local diversity (see Darlington 1943 for data) is the result of adaptive radiation and species packing via competition. The energetics of food searching differs between the zones. If the energy expended by a ground species in searching a unit area is taken a base point, then both arboreal forms, which fly and climb vertical surfaces, and burrowers producing a new section of burrow expend more. In the absence of competition from related taxa, as in the mountains of Puerto Rico for a large carabid, if ecological shift occurs in a new colonizer it should be in the direction of increased efficiency of search behavior.

The burrowing mechanism of Scaritine carabids consists of many interrelated morphological and behavioral adaptations. Evidence that several structures and proportions differ from a known burrow producer is presented above and can be interpreted as indicating a reorganization of the burrowing mechansm for a ground surface existence.

The steps taken by a species after colonizing a depauperate habitat island are: initial adaptation, ecological shift, loss of dispersal power, speciation, and adaptive radiation (MacArthur and Wilson 1967, Chap. 7). Speciation and loss of dispersal power have occurred in Antilliscaris; there is evidence for ecological shift. That an adaptive radiation has occurred in Antilliscaris is an exciting possibility and should stimulate further field work.

BEHAVIOR: A specimen of $S$. (A.) mutchleri is currently being observed. While a full report of its behavior is planned, the following observations are germane at this point. The beetle has not constructed an elaborate burrow system under conditions where substriatus and subterraneus would (Hlavac 1967). Daylight hours are spent under retreats or in concealment burrows, about 2 body lengths long, dug in areas where the soil has not been highly compressed. During the night, this animal has eaten food placed on the surface and fallen into a small pitfall trap in the center of the container 24 nights out of 37 . These fragmentary data are consistant with the hypothesis of ecological shift.

BIOGEOGRAPHY: The factors responsible for the high frequency of wing atrophy in montane carabids have been analyzed by Darlington ( I943). He pointed out ( I939, pp. 79-80) that mountains over 
$5000 \mathrm{ft}$. high on Cuba, Jamaica, and Hispaniola have endemic montane species that had become -winged on the spot. Noting that three -winged stocks on the mountains of Puerto Rico (Antilliscaris, Oxydrepanus and Colpodes estriatus Darl.) were closely related to forms known only from the mountains of Haiti, he concluded that each had reached Puerto Rico from Haiti after becoming flightless, and that mountains lower than $4000 \mathrm{ft}$. in the Antilles "are too low to induce wing atrophy among Carabidae." $S$. darlingtoni was here held to be closely related to the known species now in Antilliscaris. While I consider this species to be incertae sedis at the subgeneric level, the evidence for so doing (see systematic treatment) is not overwhelming, and this decision mainly reflects caution. In any case, questions as to the point of origin and the site of wing atrophy remain.

Long distance dispersal of montane forest-floor-inhabiting, flightless carabids to another suitable montane environment must be a rare event. Such species have all "bad" attributes that preadapt a species to be "good" colonizers (MacArthur and Wilson 1967, p. 8I). Flightless carabids are rare in the tropical lowlands (Darlington I943, pp. 44, 49-50) and would be severely selected against in areas subject to flooding. A + winged hydrophilic lowland species has many "good" preadaptations for colonization, such as occupation of an unstable habitat including many coastal sites with the potential for high population densities in hydric environments and, of course, the ability to fly.

With 3 montane spp. of Scarites on Puerto Rico, additional collecting on Haiti should turn up new species if the area species curve is remotely applicable to montane scaritine faunas (but see comments on ecological shift). When more data becomes available, I propose that the following model be tested. Major colonizing Scarites is a + winged form which burrows in a variety of shore and lowland habitats. It disperses to similar habitats on neighboring islands and subsequently invades the montane zone where -wings and flight mechanism atrophy occur along with ecological shift. Evidence for this interpretation could be obtained from detailed analysis of widely distributed + winged lowland forms. Colpodes estriatus Darlington and its allies probably represent a distinct genus (Darlington I939, p. 95). Then, of the three taxa represented in the mountains of Puerto Rico and Hispaniola by a -winged species one, Oxydrepanus, is widely distributed in the lowlands of the Greater Antilles; $O$. rufus (Putz.) is known from Cuba, Jamaica and Florida, and $O$. micans Putz. from Hispaniola and Puerto Rico; both species 
+ winged. A second montane species, O. reichoides Darl., occurs on Hispaniola.

The sophisticated taxonomy necessary to separate monophyletic from polyphyletic origins of -wings in closely related lower categories does not now exist for Scarites. Until a more refined systematics becomes available, I think it heuristic and economical to view the biogeography of Antilliscaris in light of the model presented above.

PRELIMINARY EVOLUTIONARY DIAGNOSIS: From an assumed lowland, winged and burrowing ancestor, Antilliscaris has entered the montane rain forests of Puerto Rico, become flightless, undergone an ecological shift from burrowing to ground crawling, and speciated.

BANNINGER, M.

\section{References Cited}

1935. Uber alte und neue formen der Scaritina. Ent. Blatt. 1935: 148160.

1937-39. Monographie der subtribus Scaritina (Col. Carab.). Pt. I Deutsche Ent. Zeitschr. 1937: 6-160. Pt. II-Deutsche Ent. Zeitschr. 1938: 41-181. Pt. III -Deutsche Ent. Zeitschr. 1939: 126-161.

1949. Uber Carabinae. Mittellungen der Münchner. Ent. Gesellschaft. Darlington, P. J., JR.

1939. West Indian Carabidae V. New forms from the Dominican Republic and Puerto Rico. Mem. Soc. Cubana Hist. Nat. 13: 79-101.

1941. West Indian Carabidae VI. The Jamaican species and their wings. Psyche 48: 10-15.

1943. Carabidae of mountains and islands: data on the evolution of isolated faunas, and on atrophy of wings. Ecol. Monog. 13: 37-61.

Hlavac, T. F.

1967. Observations on behavior in Scarites. Col. Bull. 21: 18-22.

LARSEN, O.

1966. On the morphology of a function of the locomotor organs of the Gyrinidae and other Coleoptera. Opus. Ent. Supp. 30:1-241.

MacArthur, R. H., and E. O. Wilson

1967. The theory of island biogeography. Princeton U. Press, 203 pp. Mutchler, A. M.

1934. New species of Carabidae from Puerto Rico. Amer. Mus. Nov. No. 686,5 pp.

SмITH, D. M.

1964. The structure and development of flightless Coleoptera: a light and electron microscopic study of wings, thoracic exoskeleton and rudimentary flight musculature. $J$. Morph. 114: 107-184. 

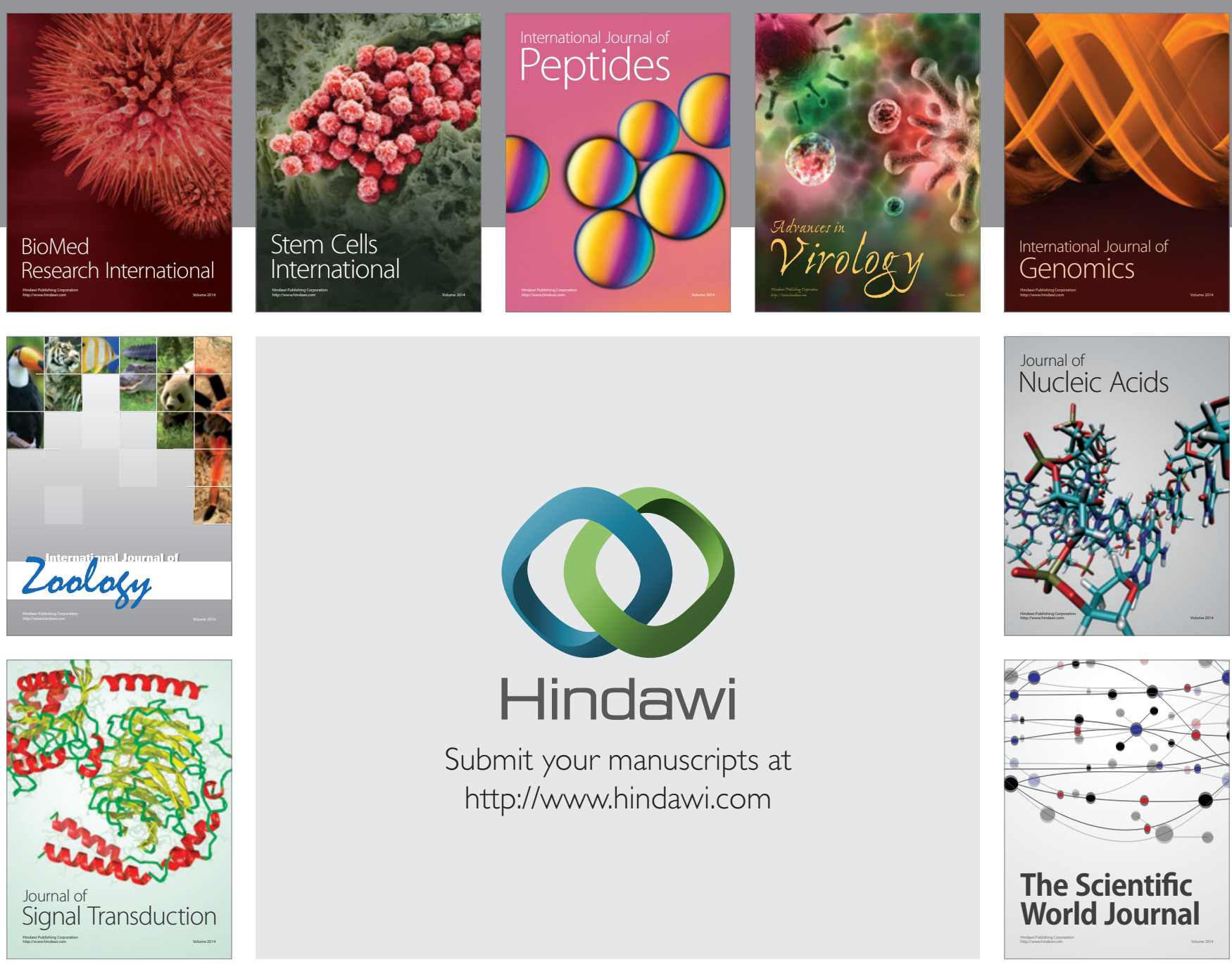

Submit your manuscripts at

http://www.hindawi.com
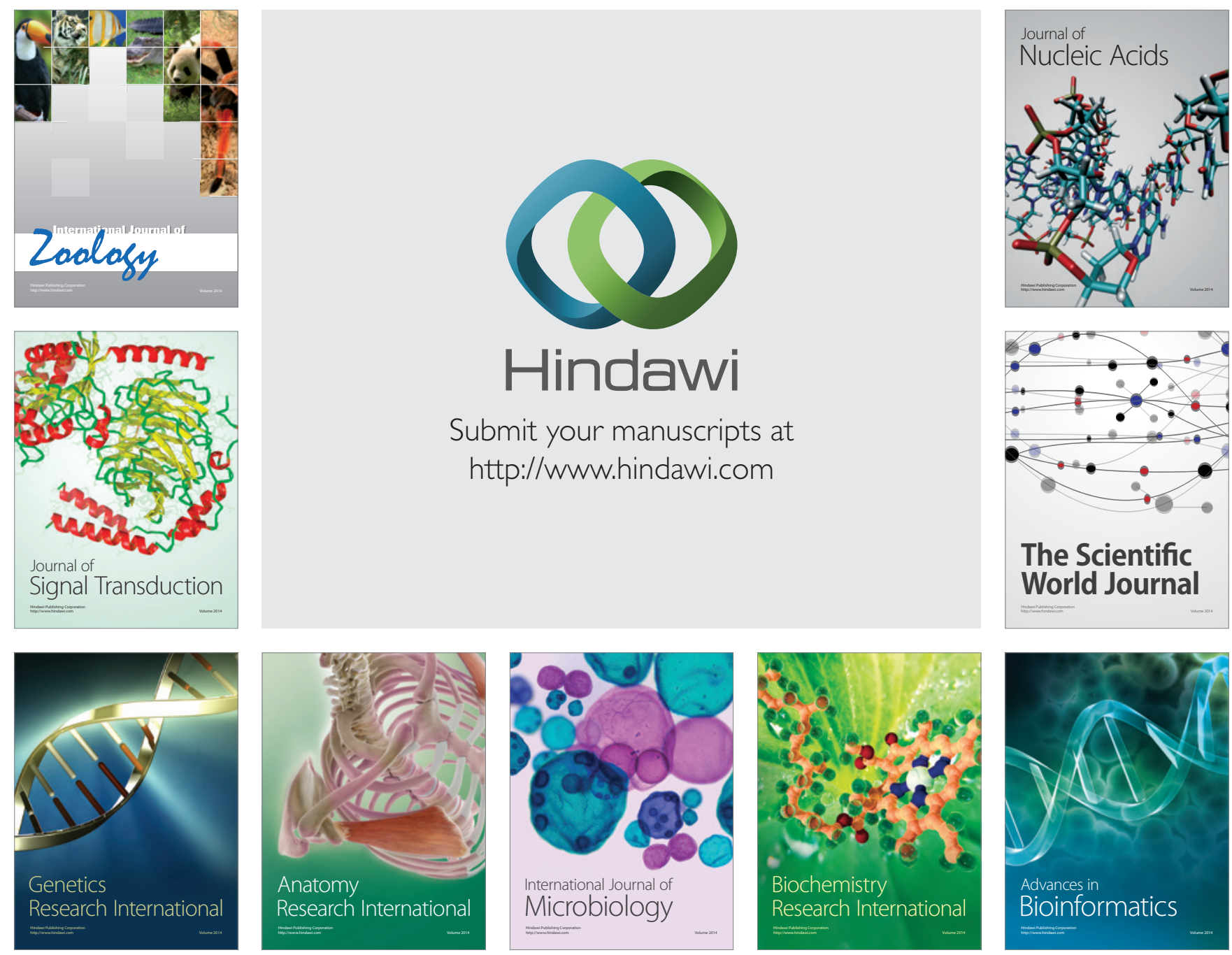

The Scientific World Journal
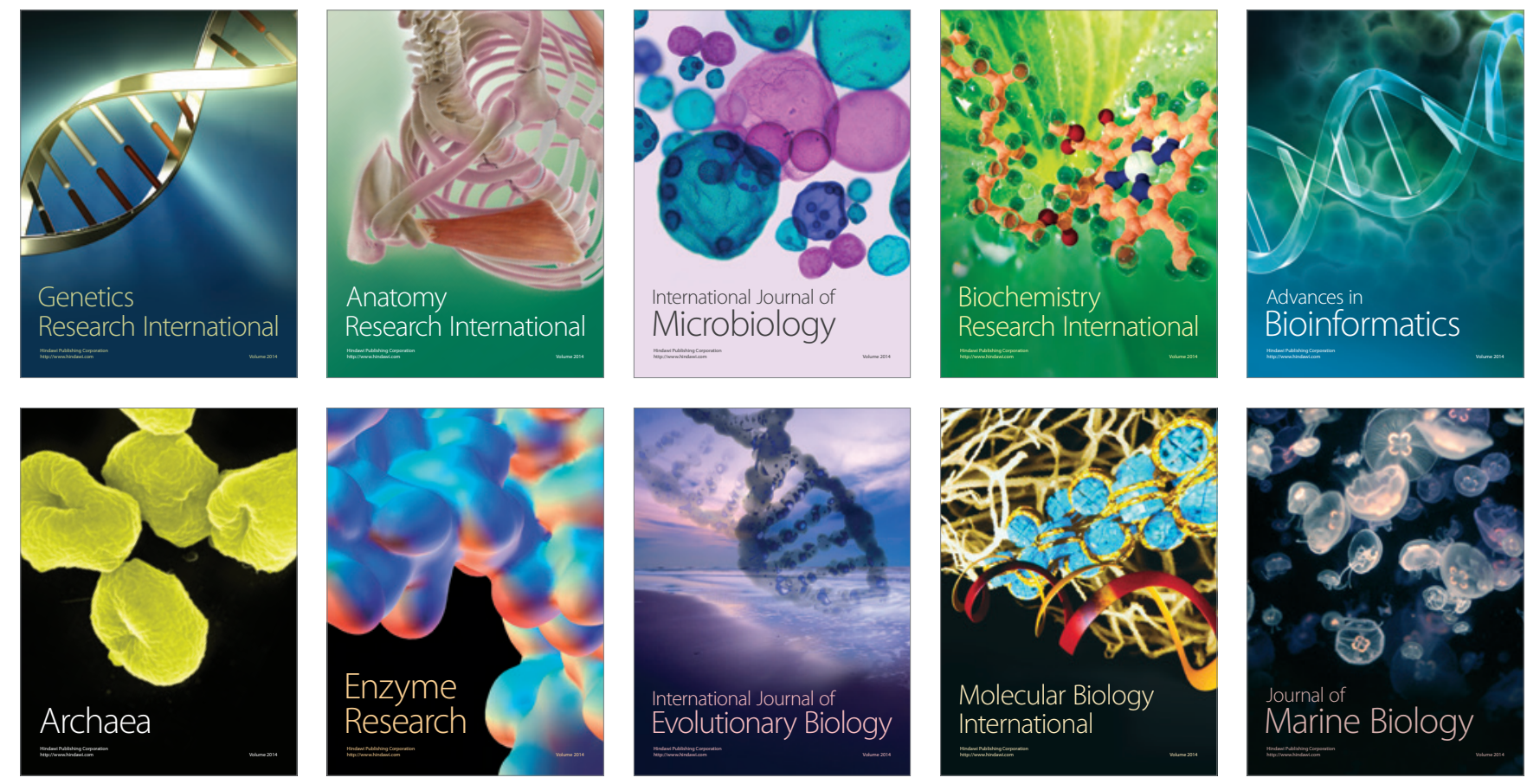